\title{
EMERGENCIA Y FORMACIÓN DE SUBJETIVIDADES HISTÓRICAS EN LOS VIDEOJUEGOS DE ACCIÓN CONTEMPORÁNEOS. EL CASO DEL DESEMBARCO DE NORMANDÍA
}

\author{
EMERGENCE AND FORMATION OF HISTORICAL SUBJECTIVITIES IN \\ CONTEMPORARY VIDEOGAMES. THE CASE OF THE D-DAY
}

\author{
Alberto VENEGAS RAMOS ${ }^{1}$ \\ Universidad de Murcia \\ correodealbertovenegas@gmail.com
}

\begin{abstract}
Resumen: Los videojuegos estadounidenses ambientados en la Segunda Guerra Mundial han recreado con frecuencia la denominada Operación Overloard. Las grandes sagas como Call of Duty (Treyarch, 2003-2017) o Medal of Honor (Dreamworks Interactive et alii, 1999-2012), con millones de unidades vendidas, han impulsado una visión heroica y nacionalista del conflicto y han dado forma a un mito histórico, a una «mitohistoria», en torno al hecho del pasado que no se corresponde con los documentos, testimonios orales y cultura material recogida, evaluada, criticada e interpretada de dicha operación. En este trabajo pretendemos evaluar tres cuestiones básicas en torno a este hecho, la creación de subjetividades históricas, la primera es el porqué de la emergencia de estas, la segunda es la forma en la que se presentan y su relación con la sociedad contemporánea y la tercera la individualidad del medio del videojuego para el transporte y divulgación de estos discursos históricos subjetivos.
\end{abstract}

Palabras clave: Historia, imagen, cultura digital, videojuegos, Desembarco de Normandía.

Abstract: American video games set in the Second World War have often recreated the so-called Operation Overloard. Sagas like Call of Duty (Treyarch, 2003-2017) or Medal of Honor (Dreamworks Interactive et alii, 1999-2012), with millions of units sold, have propelled a heroic and nationalist vision of the conflict and have shaped a historical myth, to a «mythhistory», around the fact of the past

\footnotetext{
${ }^{1}$ Departamento de Prehistoria, Arqueología, Historia Antigua, Historia Medieval y Técnicas Historiográficas. Miembro del grupo y proyecto de investigación Historia y Videojuegos 2.0, conocimiento, aprendizaje y proyección del pasado en la sociedad digital (HAR2016-78147-P).
} 
that does not correspond to the documents, oral testimonies and material culture collected, evaluated, criticized and interpreted of said operation. In this paper we intend to evaluate three basic questions about this fact, the creation of historical subjectivities, the first is the reason for the emergence of these, the second is the way in which they are presented and their relationship with contemporary society and the third, the individuality of the videogame medium for the transport and dissemination of these subjective historical discourses.

Keywords: History, image, digital cuture, video games, D-Day. 
ntroducción: El papel capital del desembarco de Normandia en el medio del videojuego.

El desembarco de Normandía se ha convertido en una regla de oro para todos los títulos que quieran asentar su acción entre el año 1939 y 1945 en Europa. Se encuentra representado en Battlefield: 1942 (Digital Illusions CE, 2002), Company of Heroes (Relic Entertainment, 2006), Medal of Honor: Frontline (DreamWorks Interactive, 2002), Medal of Honor: Allied Assault (DreamWorks Interactive, 2002), Brothers In Arms: Road To Hill 30 (Gearbox Software, 2005), Call of Duty (Infinity Ward, 2003), Call of Duty 2 (Infinity Ward, 2005) y un largo etc., Los mentados son los títulos más populares dentro de las representaciones videolúdicas de la Segunda Guerra Mundial con cifras millonarias de unidades vendidas a nivel global.

Normandía ocupa un lugar hegemónico dentro de la identidad estadounidense. En la cultura popular representa el triunfalismo de Estados Unidos ${ }^{2}$ tras el final de la cultura de la victoria ${ }^{3}$ una vez acabada la Guerra Fría. Por esta razón, la incorporación del Desembarco en los videojuegos más populares se ha convertido en un aspecto casi obligatorio ${ }^{4567}$.

El aspecto que se ha convertido en rigor no ha sido toda la operación Overlord sino una parte concreta de ella, el desembarco en la playa Omaha, denominación geográfica que engloba desde el este de Sainte-Honorine-des-Pertes hasta el oeste de Vierville-sur-Mer. Las otras cuatro playas donde los Aliados desembarcaron quedan siempre relegadas al olvido en los videojuegos de acción más populares, Utah, ocupada sin apenas oposición alemana por los estadounidenses, Sword y Gold, ocupadas por los británicos o Juno, donde desembarcaron los canadienses.

Y no solo aparece en videojuegos estadounidenses, también se ha convertido en una obligación para estudios europeos o asiáticos. Títulos no estadounidenses como el canadiense Company of Heroes representa, en su campaña para un solo jugador, dos momentos históricos, la Batalla de Normandía y la liberación aliada de Francia y permite al jugador controlar a dos divisiones, la Able Company o División No29 de Infantería del Regimiento №116 de Infantería o la Fox Company, la archiconocida División No101 Aerotransportada del Regimiento N506 de Infantería. Ambas pertenecientes al ejército de los Estados Unidos. No permite, en cambio, controlar al ejército canadiense. Esta misma línea narrativa la podemos encontrar en títulos como el mencionado Medal of Honor (Dreamworks Interactive, 1999) o Call of Duty WWII (Sledgehammer Games, 2017). Otros, como el británico Sniper

\footnotetext{
${ }^{2}$ A. Auster, A. «Saving private Ryan and American triumphalism». Journal of Popular Film and Television, 2002, 30(2), 98-104.

${ }^{3}$ T. Engelhardt. The end of victory culture: Cold war America and the disillusioning of a generation. Amherst, 2007.

${ }^{4}$ B. Colayco, «Call of Duty 2 Review». Gamespot, 2005. Consultado el 26

de junio de 2017, desde http://www.gamespot.com/pc/action/callofduty2/review.html

${ }^{5} \mathrm{~T}$. MacNamara, «Call of Duty 2: Welcome back to the hairiest WWII we've ever played» PC software, 2005. Consultado el 26 de abril de 2017 desde http://pc.ign.com/articles/661/661230p1.html

${ }^{6}$ C. Pickering. «Call of Duty 2». PC software, 2005. Consultado el 26 de abril de 2006

desde http://www.pcreview.co.uk/reviews/Gaming/Call_of_Duty_II/

${ }^{7}$ T. Cruz. «It's Almost Too Intense: Nostalgia and Authenticity in Call of Duty 2». Loading..., 2007: 1(1).
} 
Elite (Rebellion Developments, 2005) basa todas sus representaciones y reconstrucciones de la Segunda Guerra Mundial en obras estadounidenses anteriores y elimina cualquier posibilidad de controlar e incluso ver a soldados británicos. Además, la fecha de inicio del videojuego es definitoria, el año 1945, meses después del Desembarco de Normandía y seis años después del inicio de la guerra para Gran Bretaña, el 3 de septiembre de 1939, fecha en la que Inglaterra declaró la guerra a Alemania como respuesta por la invasión de Polonia el 1 de septiembre del mismo año. Es más, este videojuego está protagonizado por un soldado estadounidense. El sueco Battlefield 1942 (EA Digital Illusions CE, 2002) reproduce las mimas líneas narrativas y espaciales punto por punto siguiendo el modelo impuesto por Medal of Honor. Un camino que también recorre el francés Steel Division: Normandy 44 (Eugen Systems, 2017). La inclusión de Normandía en este título viene auspiciada de manera directa por el deseo de reproducir un elemento famoso dentro de la mitología de la guerra, como los propios responsables no dudaron en afirmar. Al ser el primer título de lo que esperan convertir en una franquicia era necesario apostar por un evento muy conocido y popular ${ }^{8}$. Una decisión respaldada por la inclusión del ejército estadounidense como principal protagonista de la campaña para un solo jugador tras tomar la playa Utah. Una segunda campaña que da inicio una vez Estados Unidos ha tomado las playas y Alemania, a la que controlaremos, comienza su contrataque. Y una tercera campaña protagonizado por el ejército británico y el intento de la toma de Caen. La narrativa estadounidense de establecer Normandía como eje narrativo del videojuego y del conflicto se ha impuesto en todas las demás representaciones del momento histórico.

Quedando esclarecida la postura hegemónica del desembarco de Normandía en los videojuegos de acción contemporáneos. Cabe preguntarse entonces el porqué de esta existencia y repetición continuada en el tiempo.

\section{Subjetividades históricas: El significado del desembarco de Normandía en la cultura popular norteamericana.}

Tom Engelhardt, en su libro The end of victory culture: Cold war America and the disillusioning of a generation (1995) afirma sin ambages que desde 1945 a 1975 se desarrolló en Estados Unidos una cultura de la victoria que tuvo en el Desembarco de Normandía su primera piedra (1998: 10). Una cultura de la victoria que terminó trágicamente en 1975, en las playas de Danang, durante la guerra de Vietnam (1998: 10). La cultura de la victoria, definida como «el lugar hegemónico que debe ocupar Estados Unidos en el mundo como resultado de sus éxitos continuados» tuvo su reflejo más importante en la cultura popular. A lo largo de los años cuarenta y cincuenta se emitieron en los cines numerosas

\footnotetext{
${ }^{8}$ "When you try to create a franchise, you have to raise expectations. The first game you do is maybe the most difficult one, because you have to project yourself. 'This is how the game is going to work.' In the beginning you have more intuition than concrete know-how. That's why I chose Normandy. It's also interesting because you have a lot of very interesting, very famous divisions there - U.S., English, Polish, French» Alexis Le Dressay, creative director de Eugen Systems en Wilson, J. (2017). «Steel Division: Normandy 44 is Paradox Interactive's grand entrance into tactical combat». VentureBeat. Consultado el 15 de febrero de 2018 desde «https://venturebeat.com/2017/03/01/steel-division-normandy44-is-paradox-interactives-grand-entrance-into-real-time-tactical-combat/».
} 
películas probélicas que incitaban al reclutamiento como, por ejemplo, la serie de documentales de Frank Capra «Why we fought?» o las populares películas D-Day, the Sixth of June (1956) y The Longest Day (1962) y se rechazaron otras que ponían en duda este ideal, como el documental Let There Be Light (1946). Este documental, dirigido por John Huston, fue rodado en 1946 pero no se hizo público hasta 1981. El motivo de este largo embargo fue el contenido de la película, el cual mostraba la vida diaria en un sanatorio mental de muchos soldados afectados por la guerra. Esta misma escena se repitió con novelas que desafiaban el discurso hegemónico, como Las aventuras de Wesley Jackson (1946), del ganador del premio Pullitzer William Saroyan. Este libro, encargado por el ejército de Estados Unidos, fue embargado hasta el final de la guerra por contener un mensaje contrario a los ideales defendidos por el Pentágono. Sin embargo a partir de los años sesenta las manifestaciones culturales cambiaron y apostaron por un fuerte antibelicismo con ejemplos tan destacados como Easy Rider (1969) o Apocalipsis Now (1979) junto a un fuerte movimiento pacifista. Esta misma opinión la comparte el historiador del cine Lawrence H. Suid quien, en su libro Guts and Glory: The making of the american military image in film (2002), afirma que tras la guerra de Vietnam las cintas ambientadas en la Segunda Guerra Mundial quedaron relegadas al olvido 9 . La cultura de la victoria se descompuso y el mito de la «Guerra buena» se desdibujó hasta la década de los años 90, momento en el que volvió con fuerza. De acuerdo a Pollard y Boggs, en su libro The Hollywood War Machine: U.S. Militarism and Popular Culture (2007), esta recuperación se debe a la situación internacional en la que se encontraba inmersa Estados Unidos ${ }^{10} \mathrm{y}$ a un claro intento por recuperar la noción de «Guerra buena» para las operaciones militares llevadas a cabo tras el final de la Guerra Fría y, especialmente, los atentados del 11 de septiembre. De acuerdo a Susan Faludi en su libro The Terror Dream (2007) ${ }^{11}$, tras los atentados de Nueva York se produjo en la cultura popular estadounidense «el regreso de Superman» (2009:64-86) citando un discurso del antiguo secretario de Defensa Donald Rumsfeld durante el 12 de septiembre de 2001 en el que afirmaba ante las fuerzas armadas que «América iba a necesitar más “héroes"» (2009:64).

Esta recuperación del héroe estadounidense la podemos observar en la cultura popular con un hito que inauguró un camino muy transitado en la actualidad, los libros de Stephen E. Ambrose ${ }^{12}$ Band of Brothers: E Company, 506th Regiment, 101st Airborne from Normandy to Hitler's Eagle's Nest

\footnotetext{
${ }^{9}$ L. H. Suid, L. H. Guts \& glory: the making of the American military image in film. Lexington. 2002, 617.

${ }^{10}$ «In cinema as in politics, World War II hovers over the landscape more than a half-century after the final surrender was signed aboard the USS Missouri. This is part nostalgia, part historical remembrance, part continued search for a "good war" to gratify the national psyche compromised by the Vietnam syndrome and dulled by a long-standing political malaise arising from a corporatized public sphere. The war, of course, was one of the epic moments of U.S. and world history, its consequences still deeply felt. But its meaning for American culture far transcends such historical specificity and is used today to justify contemporary wars and the institutionalized military. For Hollywood and the media in general, World War II persists as a source of action spectacles that gain new life with the advent of great technological refinements of military combat and communications.» (2007: 94).

${ }^{11}$ Publicado en España por la editorial Anagrama en 2009 bajo el título La pesadilla terrorista: miedo y fantasía en Estados Unidos después del 11-S.

12 Fountain, N. (2002). Obituary: Stephen Ambrose. the Guardian. Consultado el 7 de junio de 2018, desde «https:/www.theguardian.com/news/2002/oct/14/guardianobituaries.obituaries.»
} 
(1991) y Citizen Soldiers: The US Army from the Normandy Beaches to the Bulg (1997). Ambrose no tardó en convertirse en un colaborador de Steven Spielberg trabajando como asesor histórico en Salvar al soldado Ryan (1998) y estrecho colaborador en la adaptación a televisión de su libro Band of Brothers. La visión del conflicto defendida por Ambrose se convirtió, por tanto, en la más popular dado el inmenso éxito que supuso la película Salvar al soldado Ryan y el precedente que generó. Debra Ramsay, en su obra American Media and the Memory of World War II (2015) define la cinta de Spielberg de la siguiente manera: «Saving Private Ryan remediates the citizen soldier, recalibrates the visual construction of the war, and repurposes the notion of the "good war" "13 con una clara intención ya descrita por Laura Hein en su artículo «Introduction: The Bomb as Public History and Transnational Memory»: «idealized narrative of US culture, emphasizing decisiveness, bravery, simplicity, and national unity» ${ }^{14}$. Una narrativa que, como apuntaba Pollard soportaba una ideología justificadora de expansión y actuación militar tras las fronteras estadounidenses. Esta misma opinión es compartida por Vincent Casaregola en su libro Theatres of War: America's Perceptions of World War II (2009) donde afirmaba lo siguiente:

In 1991 our country also fought successfully to oust the invading Iraqis from Kuwait. America seemed proud once more of its military strength, and the publ ic memor y of our fai lures i n Vietnam had begun to recede, especially for a new, post- Vietnam generation. Thus, a simple victory narrative of the Cold War and the prospect of a "New American Century" were built on the recovered foundation of the "Good-War" Narrative of World War II, Largely ignoring the complexities and moral ambiguities of both.

Una visión compartida del conflicto de la que era plenamente consciente Ambrose, como demuestra la dedicatoria de la edición del año 2001: «Tom and Steven, like many others, are fascinated by World War. They are aware of how much all of us owe the men who fought it. They have put in a good part of their careers honoring the veterans. That is what stands». Ambrose personifica la cultura de la victoria y la asocia, de nuevo, a la Segunda Guerra Mundial, una cultura que fue amplificada y desplegada de manera masiva por las obras de Spielberg y Hanks, Salvar al soldado Ryan, Hermanos de Sangre (2001) y The Pacific (2010). Películas y series que abrieron de nuevo el apetito del público por la Segunda Guerra Mundial, como demuestra el gran número de cintas lanzadas al mercado durante los últimos años del siglo XX y los primeros del XXI: Pearl Harbor (2001), La delgada línea roja (1998), U-571 (2000), Windtalkers (2001) o La guerra de Hart (2002).

El Desembarco de Normandía ocupa un lugar preferente en todas estas obras. Tanto Hermanos de Sangre como Salvar al soldado Ryan comienzan su trama principal tras este suceso. La segunda, durante la primera media hora del metraje, se recrea en representar el desembarco en la playa Omaha y crea un referente para todos aquellos que han venido después, como tendremos ocasión de comprobar. La Operación Overlord fue extensamente representada en todos los medios culturales del momento con motivo de su 60 aniversario, 2004, año que coincidió con una fuerte utilización de la Segunda Guerra Mundial por parte del presidente de Estados Unidos George W. Bush. Dower en su

${ }^{13}$ D. Ramsay. American media and the memory of World War II. Londres, 2015, 99.

${ }^{14}$ L. Hein, y M. Selden (Eds.). Living with the bomb: American and Japanese cultural conflicts in the nuclear age. Armonk, 1997,3 . 
trabajo Cultures of War. Pearl Harbor / Hiroshima / 9-11 / Iraq (2010) ${ }^{15}$ realiza una comparación exhaustiva entre los sucesos ocurridos en Hawai durante diciembre de 1941 y los acaecidos en Nueva York durante septiembre de 2001 investigando y relatando el uso político del pasado en el llamamiento a las armas contra países como Afganistán o Iraq (2012: 36). Una relación paralela que fue elaborada por el gobierno del presidente George W. Bush quien, en un discurso realizado durante el primer aniversario del atentado contra las Torres Gemelas, afirmó: «Hoy se ha producido el Pearl Harbor del siglo XXI» (2012: 41). Una declaración de principios reafirmada con otros actos como por ejemplo el inicio de los trabajos para levantar el Memorial nacional a la Segunda Guerra Mundial en Washington durante septiembre de 2001 y abril de 2004 y los discursos ofrecidos por el entonces presidente durante la inauguración donde unía todos los conflictos bélicos estadounidenses con el mismo hilo, la defensa de la libertad y la democracia:

For more than two centuries, Americans have been called to defend the founding ideals of our democracy. On Memorial Day, a grateful Nation remembers the proud patriots who made the ultimate sacrifice in defense of liberty's blessings.

From the opening battles of the American Revolution through the turmoil of the Civil War, to World War I, World War II, Korea, and Vietnam, to the Persian Gulf and today's operations in the war on terror in Afghanistan, Iraq, and around the world, the members of our military have built a tradition of honorable and faithful service. As we observe Memorial Day, we remember the more than one million Americans who have died to preserve our freedom, the more than 140,000 citizens who were prisoners of war, and all those who were declared missing in action. We also honor our veterans for their dedication to America and their sacrifice. George W. Bush durante la inauguración del monumento Memorial nacional a la Segunda Guerra Mundial el 30 de mayo de $2004^{16}$.

La identificación que realiza el presidente entre los eventos nacidos al calor de los ataques terroristas a las Torres Gemelas el 11 de septiembre y los provocados por los bombardeos a Pearl Harbor sesenta años antes tuvo su eco en la cultura popular y también en los videojuegos. En muy pocos años aparecieron en el mercado un gran número de títulos ambientados en Afganistán o en un Oriente Medio genérico y en el frente europeo de la Segunda Guerra Mundial. Todos estos títulos compartieron una serie de puntos y elementos en común que buscaban reforzar sus lazos a través de la homogeneización de sus misiones, enemigos y objetivos.

El desembarco de Normandía, dentro de esta narrativa que equiparaba Pearl Harbor con las Torres Gemelas, era el final, el triunfo en el conflicto, ya que la anticipación de los soviéticos en la toma de Berlín les arrebató ese triunfo y la forma en la que terminó la guerra en Asia no ha sido recordada ni festejada por los Estados Unidos dada la problemática de su naturaleza nuclear.

Esta recuperación de lo que Bauman llamaría una «retrotopía» ${ }^{17}$ estadounidense, la recuperación de un pasado mítico donde refugiarse en un momento de zozobra, se tradujo al videojuego de la mano,

\footnotetext{
${ }^{15}$ Publicado en España por la editorial Pasado \& Presente, Culturas de guerra. Pearl Harbor, Hiroshima, 11S, Iraq (2012). 16 Consultado y extraído el 28 de marzo de 2018 desde «https://georgewbushwhitehouse.archives.gov/ww2/text/index.html».

${ }^{17}$ «Parecemos condenados a no pasar de ser, en el curso de la formación de dicho futuro, meros peones en el tablero y en el juego de ajedrez de otros (todavía desconocidos e incognoscibles para nosotros). Qué alivio, entonces, regresar de ese mundo misterioso, recóndito, antipático, alienado y alienante, densamente sembrado de trampas y emboscadas, al familiar, acogedor y hogareño mundo de la memoria, no siempre muy firme, pero si consoladoramente despejado y transitable:
} 
de nuevo, de Steven Spielberg y el desarrollo de la obra Medal of Honor (Dreamworks Interactive, 1999). Este título se convirtió en una referencia para el posterior desarrollo de otras representaciones del desembarco de Normandía en el medio del videojuego.

En conclusión, el desembarco de Normandía se convirtió, a través de su apoteosis en la cultura popular del país durante los años cuarenta, cincuenta y sesenta, en un hito histórico clave de la cultura de la victoria estadounidense. Esta cultura de la victoria se mantuvo vigente hasta la guerra de Vietnam. Tras la guerra de Vietnam la cultura de la victoria se fue apagando hasta el final de la Guerra Fría, momento en el que Estados Unidos tuvo que forjar un imaginario cultural que justificara su nueva posición en el nuevo orden mundial. Para forjar este nuevo imaginario volvió la vista hacia la retrotopía de la Segunda Guerra Mundial y su momento cumbre, el desembarco de Normandía, multiplicándose de nuevo este momento histórico en la cultura popular sea a través de los medios tradicionales, cine, libros y televisión, y los nuevos medios como los videojuegos. Sin embargo estas nuevas expresiones culturales distaban mucho, en forma, no en contenido, de las creadas durante la primera mitad del siglo XX y las primeras décadas de la segunda mitad.

\section{Subjetividades históricas: Nuevas formas de representar el desembarco de Normandía en el siglo} XXI.

Un ejemplo que ilustra a la perfección el cambio en la forma de representar el pasado que queremos demostrar es el momento dentro de la obra en el que comienza el desembarco. En la película The longest day (1962), una de las cintas más icónicas y populares de la batalla de Normandía, las barcas llegan a la costa una hora y veinticinco minutos después del inicio de la película. Durante todo ese momento previo el título de Ken Annakin, Andrew Marton y Bernhard Wicki despliega, a través de la adaptación de la novela homónima de Cornelius Ryan ${ }^{18}$, el contexto de la misma, los preparativos, las motivaciones, los personajes clave, etc., acontecimientos que, al final, conducen al desembarco. En cambio, en la película Salvar al soldado Ryan (1998) el desembarco comienza a los cuatro minutos de iniciarse la película sin contar con un contexto, antecedentes ni personajes. Mismo esquema que siguen videojuegos como el ya mentado Medal of Honor (1999) o el más reciente Call of Duty: WWII (2017), en el que las balas comienzan a amenazar al personaje jugador en menos de cinco minutos una vez iniciada la partida. Esta historia inmediata ligada a una imagen también inmediata es una característica de la ficción contemporánea que modifica por completo la forma en la que se representa el pasado en la cultura popular.

La imagen del videojuego contemporáneo comercial es inmediata en un doble sentido, el primero en el sentido de provocar una reacción inmediata al jugador y el segundo en el sentido de la duración,

\footnotetext{
«nuestra» memoria (y, por lo tanto, «mi» memoria, pues yo soy uno de esos «nosotros»); «nuestra» memoria (recuerdo de «nuestro» pasado, no del de ellos); una memoria que «nosotros», y solo «nosotros», podemos poseer (y, por lo tanto, usar y abusar de ella).» Z. Bauman. Retrotopía, óp. cit., 65.

${ }^{18}$ Otra de las diferencias claves es la fuente de los contenidos de las distintas obras. The longest day está basada en la novela del mismo nombre de Cornelius Ryan, periodista irlandés y estadounidense que cubrió la Segunda Guerra Mundial para la agencia de noticias Reuters y Daily Telegraph primero en Londrés y después junto a las tropas del general Patton.
} 
tanto la partida por un lado como la duración del producto en sí. Para provocar una reacción inmediata al jugador debe acudir al espectáculo, a la concisión, a la ligereza y a lugares ya conocidos por el usuario. Cuando el jugador comience una partida a un videojuego contemporáneo comercial debe conocer y saber en todo momento en qué lugar y tiempo se encuentra y cuáles son sus primeros pasos a seguir. Argumenta Luciano Concheiro en su trabajo Contra el tiempo: Filosofía práctica del instante (Anagrama Barcelona, 2016):

Al lector acelerado, marcado por permanentes golpeteos de información e imágenes, hay que proveerle de ideas al ritmo que está acostumbrado. No me interesa hacer extensos argumentos. Cuanto más corto y conciso, mejor. Más que convencer, quisiera hacer eco con la experiencia cotidiana: desencadenar el sentimiento de que ya se había percibido aquello que se plantea (2016: 16).

Al jugador y al espectador acelerado hay que proveerle de ideas al ritmo que está acostumbrado. Nada más comenzar Call of Duty WWII el jugador deberá afrontar los desafíos impuestos por el estudio de desarrollo en su reconstrucción del desembarco de Normandía en la playa de Omaha. A los cinco minutos exactos después de ejecutar el videojuego en el sistema elegida el jugador podrá contemplar este plano y la primera vez que tomemos posesión de nuestro avatar será para comenzar a disparar, inmediatamente, al enemigo. Un enemigo que no aparece ni tiene ningún peso en la trama salvo para ser disparado, otra diferencia con respecto a las obras populares de los años cincuenta y sesenta.

Al ser una imagen inmediata la que nos proponen estas obras culturales debe ser también ligera. Ya hemos hecho referencia a la falta de contexto de Salvar al soldado Ryan, Medal of Honor o Call of Duty WWII. Imagen entendida como ligera en el sentido ofrecido por Lipovetsky en su trabajo De la ligereza (Anagrama, 2016): «Un arte ligero que, como la moda, funciona poniendo entre paréntesis o reduciendo la dimensión del sentido en beneficio del asombro y la sensación inmediatos» (2016: 225). Un arte que oculta o elimina el contexto (aquello que da sentido a una obra) para dotar de un sentido muy ligero a la narrativa central de la obra. Para cumplir esta dimensión los videojuegos contemporáneos más populares, como Call of Duty WWII, ofrecen polos antagónicos claramente diferenciados (estadounidenses contra nazis ${ }^{19}$, no alemanes) por su vestimenta, colores y rasgos superficiales para que estos sean asumidos de forma inmediata por el jugador.

La ocultación y reducción del contexto a la mínima expresión y la liberación de este antes de los momentos interactivos de la partida es un hecho común en los títulos de acción más reconocidos. En todos ellos aparece en la forma de texto, no imagen, antes de comenzar la misión correspondiente. La información que recibe el jugador durante la partida en los videojuegos de acción contemporáneos tiene lugar en los momentos no interactivos de la partida. A través de conversaciones con otros

\footnotetext{
${ }^{19} \mathrm{Y}$ aquí quiero dejar de manifiesto esta idea, nazis, no alemanes o soldados del Eje, para los videojuegos populares contemporáneos estadounidenses no existen nacionalidades dentro de las filas del Partido nazi y todos aquellos enfrentados al jugador compartirán esa misma característica, la de ser nazis. Para entender este hecho es crucial comprender la diferenciación que realizó el estudio de desarrollo Sledgehammer Games entre miembros de las SS y miembros de la Wehrmacht siendo los primeros tabú para el juego multijugador y el control del usuario y siendo los segundos presentados como soldados alemanes «no nazis». Venegas Ramos, A. (2017). «¿Dónde están los soldados alemanes en los videojuegos de la segunda guerra mundial?». Presura. Consultado el 30 de marzo de 2018 desde «http://www.presura.es/2017/10/26/soldados-alemanes-videojuegos/».
} 
personajes, lectura de cartas u otros elementos escritos amén del visionado de pequeñas escenas de vídeo intercaladas entre los momentos interactivos. Esta situación predominante dentro del videojuego de acción contemporáneo refuerza la idea de evacuación del contexto para permitir desplegar la máxima espectacularidad audiovisual en los momentos interactivos, situaciones en las que llega a atrapar toda la atención del jugador ${ }^{20}$.

Una imagen que debe atrapar al jugador y también al espectador, una imagen espectáculo que sirve para «enganchar» a la obra. Espectacular en el sentido de espectáculo ${ }^{21}$, noción que hemos rescatado del trabajo de Lipovetsky y Serroy, La pantalla global: Cultura mediática y cine en la era hipermoderna (2009), y que ellos mismos definieron para el mundo del cine como:

Esta huida hacia delante se plasma totalmente en otro dominio, en las películas muy espectaculares, con mucha acción, suspense y violencia visual. Destinadas con frecuencia a un público más adolescente que adulto, las megaproducciones hollywodienses se basan en las claves de los géneros clásicos (terror, guerra, catástrofes, ciencia ficción), que renuevan con estímulos sensoriales gracias a efectos especiales, un ritmo infernal, explosiones sonoras, un desencadenamiento de violencia en alta fidelidad. No estamos ya en la estética modernista de la ruptura, sino en la estética hipermoderna de la saturación, cuyo fin es el vértigo, la estupefacción del espectador. Arrastrado por la escalada de imágenes, la velocidad de las secuencias, la exageración de los sonidos, el nuevo cine se presenta como un cine hipertélico (Lipovetsky y Serroy, 2009: 74).

Y de la obra fundamental de Debord La sociedad del espectáculo (Pre-Textos, 2015) quien, en su capítulo 7 afirmaba que «El lenguaje del espectáculo está hecho con los «signos» de la producción imperante que son, a su vez, la finalidad última de tal producción» (2015: 39) ofreciéndonos una clave esencial para comprender la cultura digital contemporánea más popular, el espectáculo es una finalidad en sí mismo.

Sobre estas tres características, inmediatez, ligereza y espectáculo, orbitan todas y cada una de las emergentes subjetividades históricas en la contemporaneidad referidas a la Segunda Guerra

\footnotetext{
${ }^{20}$ Una idea desarrollada en Venegas Ramos, A (2018). «Reflexividad y espectacularidad en el videojuego contemporáneo». Presura. Consultado el 21 de enero de 2019 desde «http://www.presura.es/2018/01/28/reflexividad-espectacularidadvideojuego/». Artículo en el que concluí: «Esta hipótesis podemos comprobarla en todos los videojuegos reunidos bajo el apelativo popular de «narrativos» o reflexivos. En todos ellos las tramas que nos presentan son más densas, más reflexivas, valga la redundancia, y más complejas que aquellos donde predomina la espectacularidad. En todos ellos el jugador posee menos capacidad de decisión para influir en su entorno, son menos «interactivos» La prueba de este hecho es evidente, si eliminamos la narrativa en un videojuego como That Dragon Cancer el juego se convierte en un imposible. Si eliminamos la narrativa de Call of Duty: World War II (Treyarch, 2017) el videojuego es igual de disfrutable, como demuestra la existencia de un modo multijugador, el principal reclamo de este tipo de títulos. De la misma manera ocurre en Super Mario Bros (Nintendo, 1985), Wolfenstein 3D (id Software, 1992) o Doom (id Software, 1993). Todos ellos titulos mucho más populares que los anteriormente mencionados. Por lo tanto, y para acabar, en el videojuego contemporáneo más popular ocurre que cuando los procesos son más importantes que los sujetos el contexto de la trama y su reflexividad se resienten. Una hipótesis que nos lleva a preguntarnos una serie de cuestiones ¿Es posible contar historias que apelen a la reflexividad del jugador dentro de un envoltorio de imágenes espectaculares? ¿Debe el videojuego despojarse de interactividad para dotarse de reflexividad? ¿Es posible aunar reflexividad e interactividad? Interrogantes que intentaremos desvelar en próximos trabajos.»

${ }^{21}$ De acuerdo a la tercera acepción ofrecida por la Real Academia de la Lengua Española la palabra espectáculo se entiende como: Cosa que se ofrece a la vista o a la contemplación intelectual y es capaz de atraer la atención y mover el ánimo infundiéndole deleite, asombro, dolor u otros afectos más o menos vivos o nobles.
} 
Mundial y el desembarco de Normandía. La batalla de Normandía se ha convertido en espectáculo donde las únicas partes que aparecen son los combates singulares entre soldados en una playa concreta, eliminado o relegando al olvido la preparación, los antecedentes, las causas, los otros escenarios, el papel del enemigo, etc. Todo ello nos conduce a aligerar el momento presentando al gran público dos bandos enfrentados, estadounidenses y nazis, fácilmente distinguibles. Esta decisión, muy utilizada, olvida a otros muchos ciudadanos de otras muchas nacionalidades que también participaron en el conflicto. Todo ello con el objetivo de encumbrar una visión particular y triunfalista del conflicto que elimina la reflexión en el ara del espectáculo. El papel de este momento histórico se sigue manteniendo intacto, representar la cultura de la victoria, sin embargo la forma en la que se ha presentado ha cambiado a favor de una mayor inmediatez, ligereza y espectacularidad que ha visto en el videojuego y el cine de acción contemporáneo sus mejores cauces y medios de expresión.

\section{Subjetividades históricas: La consolidación de las nuevas formas de representar el desembarco de Normandía en el siglo XXI.}

En los apartados anteriores hemos establecido la posición hegemónica del desembarco de Normandía en el medio del videojuego, el significado de dicho momento histórico en el cine estadounidense y las nuevas formas que ha tomado en el siglo XXI. También hemos querido demostrar y dejar en evidencia la búsqueda, por parte del videojuego, del Desembarco de Normandía en el cine en lugar de la Historia. Ante estas cuestiones es necesario abordar otros dos puntos de capital importancia, las razones que permiten la repetición y la permanencia de esta subjetividad histórica en la cultura popular contemporánea y la segunda las potenciales consecuencias para el conocimiento del pasado a través de medios como el videojuego o el cine de acción.

\section{La formación y repetición de retrolugares en la cultura popular contemporánea.}

Sobre el primer punto, la repetición y permanencia de subjetividades históricas en la cultura popular contemporáneo, vamos a acudir a un concepto acuñado por nosotros mismos, $\left\langle\right.$ retrolugar» ${ }^{22} \mathrm{y}$ definido como: «Elemento que evoca o intenta reconstruir un pasado idealizado, ligero, simplificado, fácilmente reconocible y fuera del tiempo con el objetivo de servir como objeto de consumo cultural o adorno estético.») Ya hemos establecido que el desembarco de Normandía se ha convertido en un espectáculo ligero e inmediato que ha registrado un inmenso éxito comercial ${ }^{23}$, un éxito comercial que el mismo director, Steven Spielberg, llevó al videojuego, Medal of Honor, y a la televisión, Hermanos de Sangre, creando así una trinidad transmediática de un éxito abrumador que ha sido repetida desde entonces para intentar continuar y repetir su éxito comercial. Richard Sennett en su libro La cultura

\footnotetext{
${ }^{22}$ Concepto presentado y defendido en el artículo «Retrolugares, definición, formación y repetición de lugares, escenarios y escenas imaginados del pasado en la cultura popular y el videojuego», Revista de Historiografía (RevHisto). № 28 - Año XV (1/2018), pp. 323-346.

${ }^{23}$ De acuerdo a las cifras de recaudación ofrecidas por el portal IMDb (Internet Movie Data Base) Salvar al soldado Ryan consiguió más de 480 millones de dólares durante su permanencia en los cines y fue proyectada en cerca de 2.500 pantallas tan solo en los Estados Unidos.
} 
del nuevo capitalismo trataba esta idea aportándonos un punto de vista capital para entender la permanencia y repetición de estas subjetividades históricas:

El consumidor busca estimular la diferencia entre bienes cada vez más homogeneizados. El consumidor, hombre o mujer, se asemeja a un turista que va de una ciudad clónica a otra y que en ambas visita las mismas tiendas y compra los mismos productos. Pero ha viajado (2013: 127-128)

El jugador que inicie una partida en Call of Duty: WWII comenzará en Normandía y seguirá ascendiendo, en la piel digital de un soldado estadounidense, hasta Alemania. En todos los títulos de la saga ambientados en la guerra aparecerán los mismos elementos narrativos e históricos, la única diferencia será la espectacularidad de la imagen, que se irá haciendo cada vez mayor y más dominante mientras más avancemos en el tiempo. Es la disparidad entre Call of Duty y Call of Duty: WWII, dos títulos con catorce años de diferencia entre ellos, y esta es la misma que los separa de Sniper Elite, Company of Heroes o Battlefield 1942. En definitiva, la repetición de representaciones y reconstrucciones de la Segunda Guerra Mundial responde a dos cuestiones principales: la primera, reproducir obras ya populares con la intención de alcanzar un éxito similar; la segunda, ofrecer al consumidor una experiencia ya conocida basada en obras cinematográficas anteriores, que logren estimular su «cámara de resonancia».

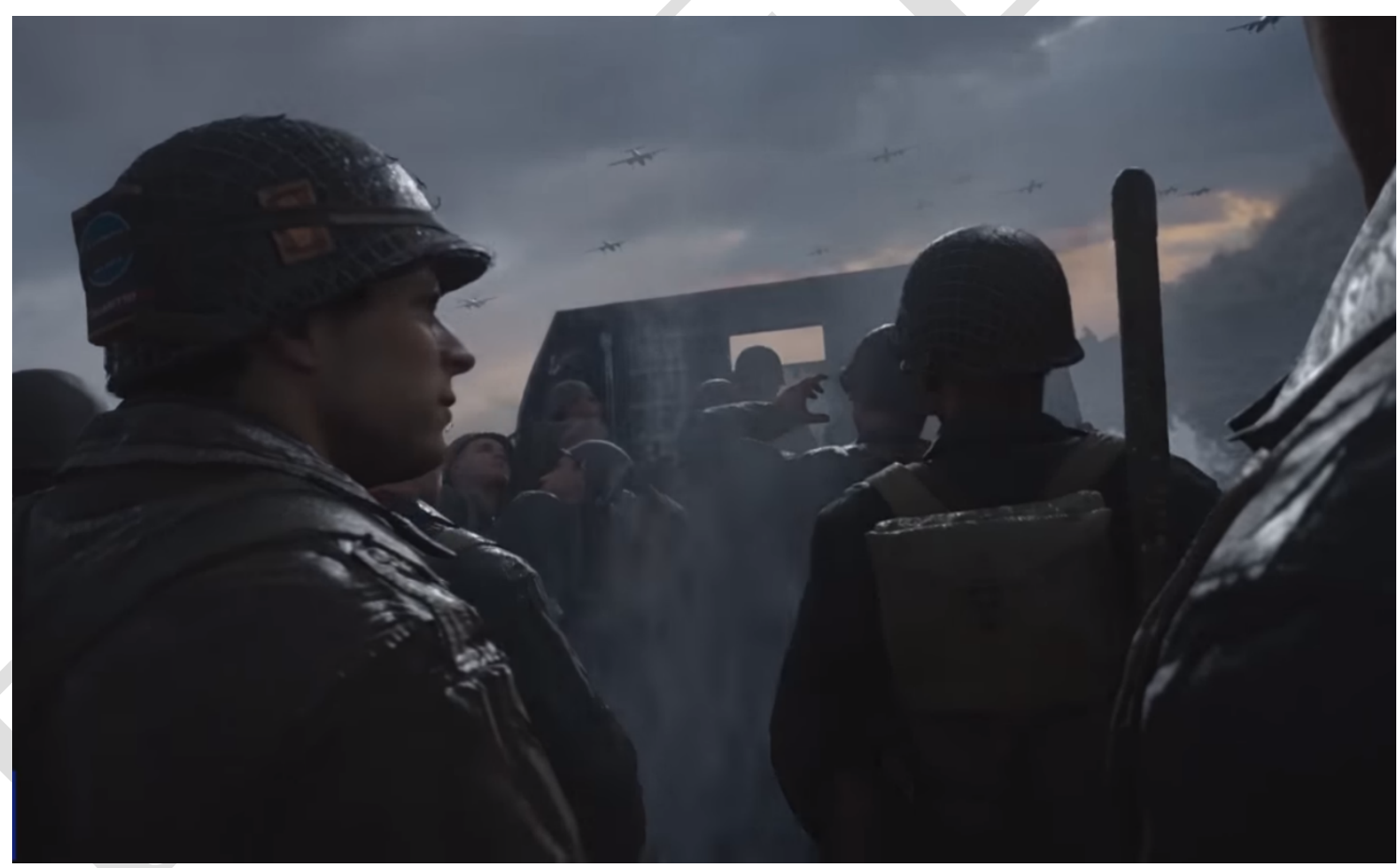

Figura 1: Captura de pantalla de Call of Duty WWII (2017) 


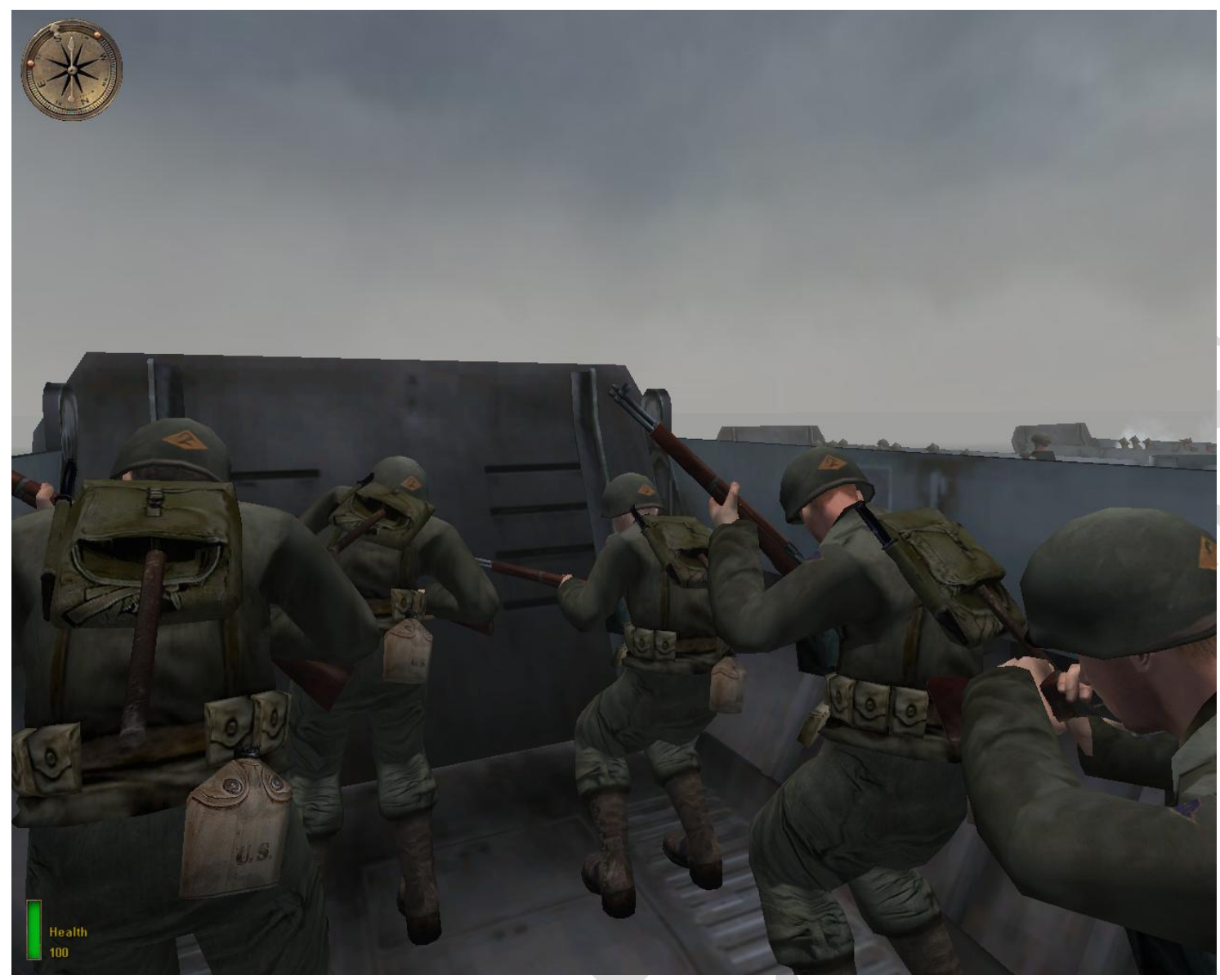

Figura 2: Captura de pantalla de Medal of Honor: Allied Assault (2002)

La problemática de la imagen espectacular, ligera e inmediata para la transmisión de la información histórica.

Las características básicas de la imagen en nuestra contemporaneidad (espectacularidad, ligereza e inmediatez) y la necesidad de acudir a lugares preparados adecuadamente por el cine de masas para ofrecer una identificación inmediata al jugador del espacio y el tiempo en el que se encuentra, provocan el empobrecimiento, la uniformidad y la tergiversación, cuando no deformación voluntaria, de la información histórica contenida en la cultura digital que debe adaptarse a estas características para poder ocupar un lugar visible dentro del mercado cada vez más acelerado del videojuego.

El pasado se convierte en un complemento que busca reforzar la espectacularidad de la imagen representada. La historia, en la cultura popular digital, no cuenta con un valor didáctico o crítico, sino de diversión y entretenimiento y por lo tanto los contenidos acerca del ayer deben adecuarse a estas características, especialmente si lo que se busca es una imagen espectacular del pasado. Para ello se vacía de contexto el momento escogido y se concentran los esfuerzos en una representación hiperrealista de la cultura material con especial atención a armas y equipamiento militar junto a la posición dominante de espacios, personajes y monumentos icónicos que realcen la identificación del tiempo pasado seleccionado. 
Todas estas decisiones no existen exclusivamente en el videojuego sino que son un elemento recurrente dentro de las representaciones populares de la historia y podemos apreciarlas especialmente en el cine contemporáneo. Lipovetsky y Serroy en su libro La pantalla global: Cultura mediática y cine en la era hipermoderna (Anagrama, Barcelona, 2009) afirman que: «Después de Spielberg y la generación neohollywoodense de finales de los años setenta, adquiere gran importancia otro parámetro: la velocidad, el ultramovimiento, el ritmo infernal» (2009: 78). Todas estas características se encuentran presentes dentro del videojuego. Ya hemos referenciado la cantidad de tiempo que lleva a Call of Duty WWII situar al jugador disparando en las playas de Normandía, menos de cinco minutos. Y lo mismo ocurre con otros videojuegos contemporáneos donde la acción es presentada de manera inmediata sin tiempo para la reflexión o el contexto de un momento determinado.

La velocidad y el ritmo ultraligero de la acción en el videojuego contemporáneo más popular obliga a aligerar el peso de las narraciones históricos hasta reducirlo a la esencia compuesta por lugares comunes, tópicos y elementos icónicos que sean instantáneamente absorbidos e identificados por el jugador.

\section{Conclusión.}

En definitiva, el desembarco de Normandia ha emergido como una de las subjetividades históricas más importantes en el medio del videojuego y las representaciones digitales de la Segunda Guerra Mundial. Un momento histórico que ha tenido un lugar predominante dentro de la cultura de la victoria estadounidense y ha vuelto a ocupar un papel predominante en la década de los años 90 en adelante. Una idea que ha tenido en los videojuegos y el cine de acción contemporáneo su mejor medio de expresión a través de la adaptación de este mensaje al siglo XXI mediante el uso de imágenes espectaculares, ligeras e inmediatas. Un formato que ha cosechado un gran éxito comercial provocando su permanencia y repetición en numerosos títulos posteriores tanto estadounidenses como europeos o asiáticos. Un formato que ha servido para desplegar y popularizar una visión subjetiva de la guerra y el desembarco de Normandía alejado por completo del oficio del historiador y convertido en un producto de entretenimiento.

Las subjetividades históricas más populares y emergentes dentro de la cultura digital contemporánea acuden al cine de masas para conseguir legitimarse a través de la activación de la «cámara de resonancia» del consumidor sin llegar a cuestionarla ni separarse de ella. Esta decisión convierte a los videojuegos históricos en un producto mercantilizado cuya principal finalidad es la evasión y el entretenimiento realizado por y para el presente más inmediato. Se vacían de significado y se emplean como escenario donde se suceden imágenes espectaculares. Al reducirse el contexto, no mencionar causas o antecedentes, el momento histórico desaparece y se difumina para aparecer como un mero recurso estético de una obra dramática soportada por otros elementos como la acción y la violencia. Todos los videojuegos mencionados en este artículo apuestan por la visión individual del soldado (ciudadano) en el campo de batalla olvidándose, de nuevo, de la visión global del momento y reducen el conflicto a una lucha entre «buenos y malos» fácilmente identificables por el consumidor. 
Los tres rasgos dominantes que hemos desarrollado en las formas de representación histórica en la cultura popular del siglo XXI, espectacularidad, ligereza e inmediatez, deforman el pasado hasta convertirlo en paquetes asimilables y fácilmente identificables por el jugador que tan solo sirven para diferenciar productos muy similares y aportar un plus de realismo a la obra.

\section{Referencias bibliográficas}

Auster, A (2002): «Saving private Ryan and American triumphalism». Journal of Popular Film and Television, 2002, 30(2), 98-104.

Boogs, C., Y Pollard, T. (2016): The Hollywood War Machine: U.S. Militarism and Popular Culture. Routledge. Londres.

CRUZ, T. (2007): «It's Almost Too Intense: Nostalgia and Authenticity in Call of Duty 2». Loading..., $1(1)$.

DeBord, G. (2016): La sociedad del espectáculo. Pre-Textos, Valencia.

Dower, J. (2010): Cultures of War: Pearl Harbor / Hiroshima / 9-11 / Iraq. W. W. Norton \& Company, Nueva York.

(2012): War without mercy. Race and Power in the Pacific War. Pantheon Books. Nueva York.

Engelhardt, T. (2007): The end of victory culture: Cold war America and the disillusioning of a generation. University of Massachusetts Press, Amherst.

HeIn, L y SELDEN, M. (Eds.). (1997): Living with the bomb: American and Japanese cultural conflicts in the nuclear age. Routledge, Armonk.

Hess, A. (2007): «"You Don't Play, You Volunteer”: Narrative Public Memory Construction in Medal of Honor: Rising Sun». Critical Studies in Media Communication, 24 (4), pp. 339-356.

Lipovetsky, G. (2016): De la ligereza. Hacia una civilización de lo ligero. Anagrama, Barcelona.

Lipovetsky, G., Y Serroy, J. (2009): La pantalla global. Cultura mediática y cine en la era hipermoderna. Anagrama, Barcelona.

(2010): La cultura - mundo. Respuesta a una sociedad desorientada. Anagrama, Barcelona.

RAMSAY, D. (2015): American media and the memory of World War II. Routledge, Londres.

SARTORI, G. (2012): Homo Videns: La sociedad teledirigida. Taurus, Barcelona.

SuID, L. H. (2002): Guts \& glory: the making of the American military image in film. The University Press of Kentucky, Lexington.

Venegas Ramos, A. (2017): «¿Dónde están los soldados alemanes en los videojuegos de la segunda guerra mundial?». Presura. Consultado el 30 de marzo de 2018 desde «http://www.presura.es/2017/10/26/soldados-alemanes-videojuegos/». 
(2018): «Entre el cine y el videojuego. Ética y estética en las producciones sobre la Segunda Guerra Mundial». En JIMÉNEZ ALCÁZAR, J. F., y RODRÍGUEZ, F, G. (2018): Colección Historia y Videojuegos $n^{\circ} 5$ : Videojuegos e historia: entre el ocio y la cultura. Universidad de Murcia: Servicio de Publicaciones, Murcia.

(2018): «Retrolugares, definición, formación y repetición de lugares, escenarios y escenas imaginados del pasado en la cultura popular y el videojuego», Revista de Historiografía (RevHisto). No 28 - Año XV (1/2018), pp. 323-346. 